\title{
Silindir Etrafındaki Kararsız Akışın Farklı Türbülans Modelleri ile Sayısal Olarak İncelenmesi
}

\section{Numerical Investigation of Unsteady Flow around the Circular Cylinder with Different Turbulence Models}

\author{
Geliş / Received: 06/05/2019
}

\author{
İlyas KARASU ${ }^{1 *}$
}

\author{
Revize / Revised: 24/05/2019
}

Kabul / Accepted: 28/05/2019

$\ddot{O}$

z- Bu çalışmada, kritik altı olan 5000 Reynolds sayısında silindir etrafındaki kararsız akış farklı türbülans modelleri ile sayısal olarak incelenmiş ve bu modellerin performansları test edilmiştir. Çalışmada, aynı

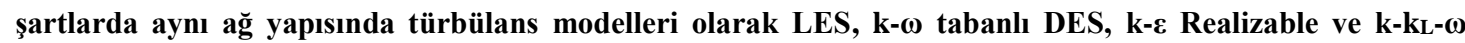
transition modelleri kullanılmıştır. Benzeşimlerden elde edilen sayısal ortalama akış yapısı, sürükleme kuvvet katsayısı ve Strouhal sayısı sonuçları, literatürden benzer şartlarda yapılan bir deneysel çalışmanın sonuçlarıyla kıyaslanmıştır. İncelenen parametreleri LES ve DES modelleri düşük hata ile tahmin etmiş̧ir. Diğer modellerden $k-k_{L}-\omega$ transition

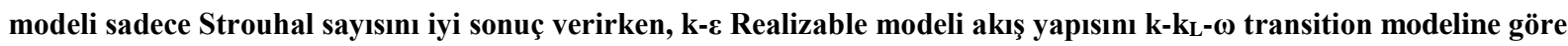
daha iyi verse de Strouhal sayısı ve sürüklenme katsayısı değerini daha yüksek hata ile vermiştir.

\section{Anahtar Kelimeler- Kararsız Akış; Küt Cisim; Kritik altı Reynolds Sayısı; Türbülans Modeli}

\begin{abstract}
$A$ bstract- In this study, a numerical investigation on the unsteady flow over a circular cylinder using various turbulence models at a sub-critical Reynolds number 5000 were conducted and performances of those models were assessed. The LES, $k-\omega$ based DES, $k-\varepsilon$ Realizable and $k-k_{L}-\omega$ transition models were used as the same grid structure and turbulence models under the same flow conditions. Numerical results on the mean flow structures, drag force coefficients, Strouhal numbers were compared with an experimental study in the literature which performed at similar flow conditions. The LES and DES models were predicted these parameters with very low errors. While the prediction of $k-k_{L}-\omega$ transition model on the Strouhal number agrees well with experiments, predictions on the other parameters do not agree well. However, prediction of the $k-\varepsilon$ Realizable model on the mean flow structure is better than $\mathrm{k}-\mathrm{k}_{\mathrm{L}}-\omega$ transition model, this model predicted drag coefficient and Strouhal number with high error.
\end{abstract}

Keywords- Unsteady Flow; Bluff Body; Subcritical Reynolds Number, Turbulence Model

\section{I.GİRIŞ}

Küt cisim aerodinamiği araştırmaları için en çok kullanılan geometri silindirdir ve birçok mühendislik uygulamasında da silindir etrafındaki akışla karşılaşılır [1]. Çalışılan Reynolds sayısında deneysel olarak silindir etrafındaki akış birçok araştırmacı tarafından çalışılmış ve fiziği ortaya konulmuştur. Silindir etrafındaki anlık akış yapısı incelendiğinde silindir üzerinde akış ayrıldıktan sonra girdap kopmalarının olduğu ve çalkantılı bir akış yapısının olduğu gösterilmiştir. Periyodik girdaplı akış yapısı ve ölü akış bölgesindeki yüksek çalkantılar gürültü veya titreşime neden olabilir [2,3]. Silindir etrafındaki ortalama akış yapısı, ters akış bölgesinde birbirine ters yönde dönen bir çift girdap, bir adet ayrılma noktasından oluşur. Najafi vd. [4] tarafından belirtildiği gibi literatürde aynı Reynolds sayısında sürüklenme katsayısı ve ters akış bölgesinin uzunluğu gibi değerler, blokaj oranı, serbest akışın türbülans seviyesi, yüzey pürüzlülüğü gibi etkenlerden dolay çalışmalarda farklılıklar göstermektedir.

1*Sorumlu yazar iletişim: ikarasu@atu.edu.tr_(https://orcid.org/0000-0003-3138-6236)

Havacılık ve Uzay Mühendisliği Bölümü, Adana Alparslan Türkeş Bilim ve Teknoloji Üniversitesi, Adana, Türkiye 
Deneysel çalışmaların yanı sıra küt cisimler etrafındaki akışı inceleyen sayısal çalışmalar artmaktadır. Young ve Ooi [5], 3900 Reynolds sayısında iki boyutlu (2D) ve üç boyutlu (3D) URANS (Unsteady Reynolds Averaged Navier-Stokes-Kararsız Reynolds Ortalamalı Navier-Stokes) sonuçlarını LES (Large Eddy SimulationBüyük Girdap Simülasyonu) ile kıyaslamıştır. 3D URANS sonuçları 2D’ye nazaran daha tutarlı olmasına rağmen, LES sonuçları hem 2D hem de 3D URANS sonuçlarından daha iyi çıkmıştır. Palkin vd. [6] LEVM (linear eddyviscosity model- lineer girdap-viskozite model) ve RSM (Reynolds Stress Model-Reynolds Stress Modeli) yaklaşımlarıyla $\mathrm{Re}=3900$ ve $\mathrm{Re}=140000$ için URAN çözümleri yapmıştır. 140000 Reynolds sayısında, sınır tabaka içerisinde türbülansa geçişin kısa olmasından dolayı akış daha kararlı olduğundan daha tutarlı sonuçlar elde edilmiştir. Prsic vd. [7] silindir etrafındaki akışı 3900 ve 13100 Reynolds sayısında çözmüş ve DNS (Direct Numerical Simulation- Doğrudan Sayısal Simülasyon) sonuçları ile kıyaslamıştır ve LES sonuçlarının DNS ile oldukça uyumlu olduğunu göstermişlerdir. Rosetti vd. [8] 2D URANS modellerinin Reynolds gerilmelerini doğru tahmin etmesinden kaynaklı olarak ölü akış bölgesini daha kısa ve sürükleme kuvvetini ise yüksek tahmin ettiğini göstermişlerdir. Mannini [9] $\mathrm{Re}=21600$ 'de dikdörtgen ve köprü kesiti etrafındaki akışı URANS ve DES ile kıyaslamışlardır. DES her zaman deneye daha yakın sonuçlar vermiş ve dikdörtgenin kenar oranları 5:1 oranında iken 2D URANS kısmen iyi sonuç verse de 1:5 oranında ne 2D ne de 3D URANS 3D DES kadar iyi sonuç verebilmiştir. Kim vd. [10] silindir etrafındaki akışı 5500 ve 41300 Reynolds sayılarında LES kullanarak analiz etmiştir. Düşük olan Reynolds sayısında SGS (Sub Grid Scale-Alt Grid) modeli kullanılırken yüksek Reynolds sayısında hem ağ sayısı arttırılmış hem de k-SGS modeli kullanılmıştır. Her iki Reynolds sayısında da deneysel verilere yakın sonuçlar elde edilmiştir. Sidebottom vd. [11], 3900 Reynolds sayısında alt grid ölçeği (SGS) türbülans modeli, duvar modeli, ayrıklaştırma metodu ve ağ çözünürlüğünün etkisini araştırmıştır. Merkezi ayrıklaştırma yukarı yönlü şemadan daha iyi sonuç vermiştir. Smagorinsky modeli ile tek denklemli girdap viskozite modeli arasında çok küçük farklar bulunmuştur. Kullanılan duvar modelinin özellikle silindirin arkasındaki akış yapısı üzerinde oldukça etkili olduğu görülmüştür. You ve Kwon [12] 3000000 Reynolds sayısında silindir etrafındaki akışı RANS modeli olan Spalarat-Allmaras (S-A) modeli, S-A tabanlı DES (Dettached Eddy Simulation-Bağımsız Girdap Simülasyonu) ve k- $\omega$ SST tabanlı SAS (Scale-Adaptive Simulation-Ölçek Adaptif Simülasyon) modelleri ile akış yapısını incelemiş ve DES yaklaşımında yıkım terimini aktive edildiğinde ve SAS yaklaşımında da özgül dağılma hızı arttırıldığında RANS sonuçlarına göre daha iyi sonuçlar elde etmişlerdir. Tian vd. [13] farklı açıklık oranlarında dikdörtgen etrafındaki akışı 21400 Reynolds sayısında k- $\omega$ SST türbülans modeli kullanarak incelemiş̧lerdir. Ortalama sürükleme katsayısı $C_{D}$, açıklık oranı ile 1 ile 0.6 arasında deneysel çalışmaya yakın olarak tahmin edilmişken daha düşük açıklık oranlarında daha yüksek hata ile tahmin edilmiştir. Taşıma katsayısındaki RMS değeri $C_{\text {Lrms }} 1$ açıklık oranında deneysel sonuçlara yakın çıkarken diğerlerinde yakın sonuç vermemiştir. Fakat bazı durumlar farklı LES ve DES çalışmalarına da benzerlik göstermiştir. Açıklık oranına bağlı St sayısı genel olarak deneysel çalışmalarla benzerlik göstermiştir. Soydan vd [14] silindirik köprü ayakları etrafındaki akışı k-E modelinin 3 farklı türünü de kullanarak LDA (Lazer Doppler Anemometer-Lazer Doppler Anemometresi) sonuçları ile kıyaslamışlardır. Hız profili tahmini konusunda Realizable k- $\varepsilon$ modeli daha başarılı olmuş ve akışın 3D olarak değerlendirilmesinin daha doğru olacağı sonucuna varılmıştır.

Sonuç olarak, literatürdeki çalışmalardan da görüldüğü gibi kritik altı Reynolds sayılarında ters basınç gradyenleri, türbülansa geçiş süreci etkisi ile akışın kararlı bir rejimde olmamasından dolayı küt cisim etrafındaki daimi olmayan (kararsız) akışı sayısal olarak analiz etmek zordur. Bu çalışmada, kritik altı Reynolds sayısındaki (5000) bu kararsız akışı farklı modellerle benzeşimler yapılarak performansları deneysel çalışma ile kıyaslanması amaçlanmıştır. Bu performans kıyaslaması deneysel ve sayısal zaman ortalamalı akım çizgileri, zaman ortalamalı sürükleme katsayısı $\left(\mathrm{C}_{\mathrm{D}}\right)$ ve Strouhal sayısı $(\mathrm{St})$ değerleri ile yapılmıştır.

\section{II.MATERYAL VE METOT}

Tüm sayısal çözümlerde, GAMBIT yazılımı kullanılarak oluşturulmuş O tipi yapısal ağ kullanılmıştır. Şekil 1 çalışma alanın ölçülerini silindirin çapı D cinsinden (ölçeksiz) göstermektedir. Tüm akış alanını oluşturan dış silindirin çapı 50D, akış alanın kalınlığı z ekseni boyunca $\pi \mathrm{D}$ olarak verilmiştir. Şekil 2a ağ yapısının genel görünümü ve Şekil 2b silindir etrafındaki ağ yapısını göstermektedir. Silindirin çap1 200, silindir dışındaki bölgede y ekseni 150 parçaya bölünmüştür, silindir etrafındaki ağ daha da sıklaşmış daha sonra düzenli olarak giriş ve çıkışa doğru giderek açılmıştır. Silindire verilen $\pi \mathrm{D}$ kadar kalınlık oluşturulurken 48 eşit parçaya bölünmüştür. Sidebottom vd [11] tarafından da belirtildiği gibi tarafindan da belirtildiği gibi z ekseninde bu kalınlık ve düğüm noktası akışı modellemek için yeterlidir. 


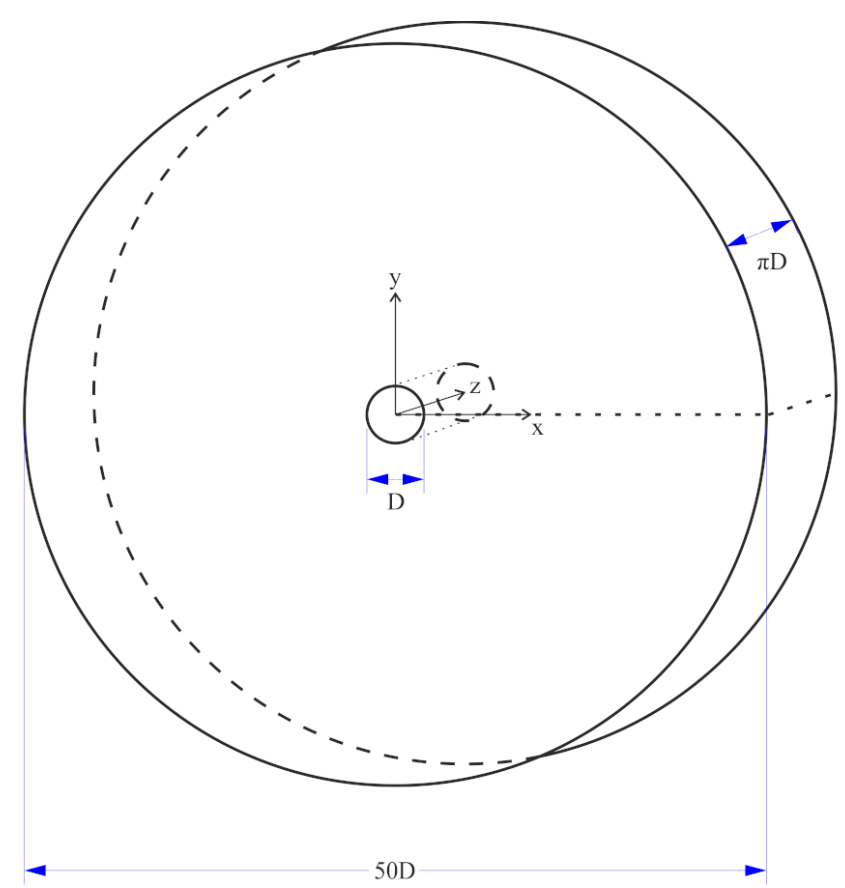

Şekil 1. Akış alanın silindirin çapı cinsinden ölçüleri

Ağda toplam 1479800 adet düğüm noktası bulunmaktadır. Dıştaki silindirin ilk yarısındaki yüzey hızı girişi, diğer yarısındaki yüzey basınç çıkışı ve dıştaki silindirin iki yüzeyi de simetri olarak seçilmiştir. Çözümlerin ağdan bağımsızlığını göstermek için 4 farklı düğüm noktasına sahip ağlarda çözümler yapılmıştır. Şekil 3 farklı düğüm noktasına sahip ağlardaki $C_{D}$ değerlerini göstermektedir. Şekilden de görüldüğü üzere 4 farklı düğüm noktasına sahip ağ yapısında $C_{D}$ arasındaki fark gayet düşüktür. Yaklaşık 1.200.000 olan düğüm noktasından sonra $\mathrm{C}_{\mathrm{D}}$ değeri neredeyse hiç değişmediğinden dolayı 1479800 düğüm yapılı ağ seçilmiştir.

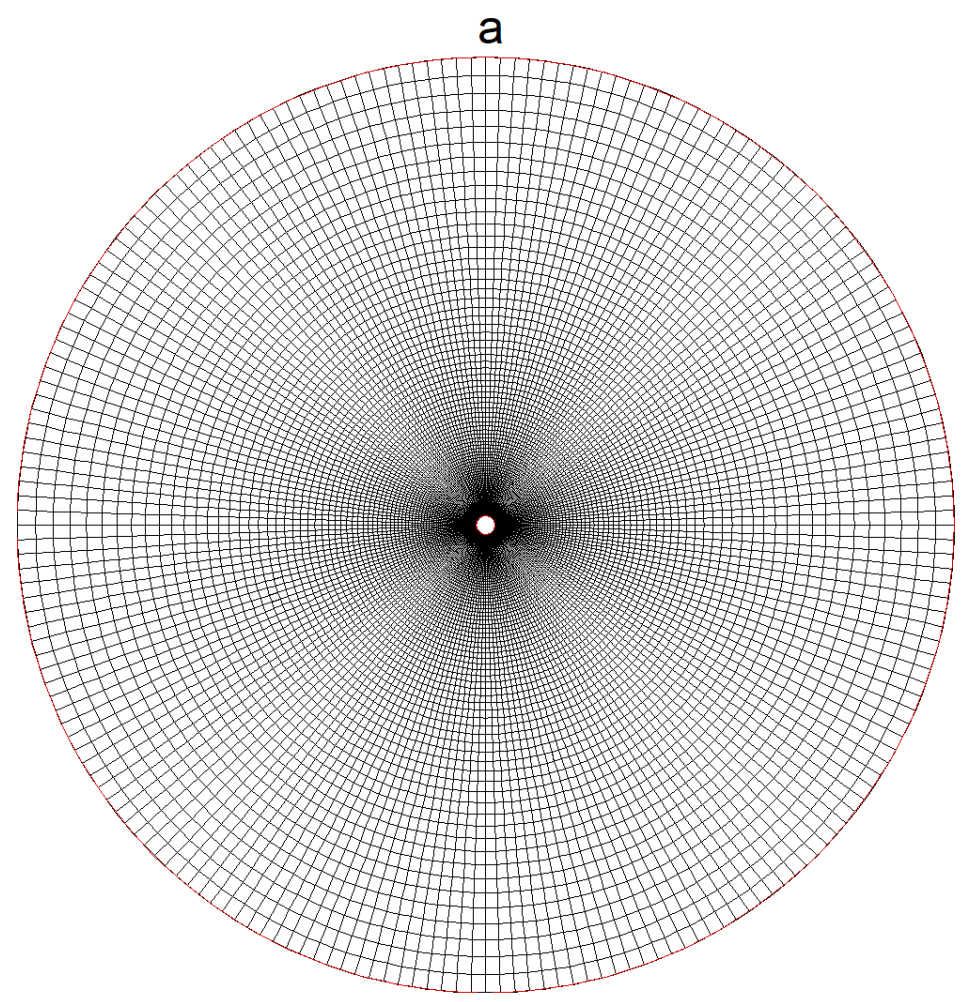

b

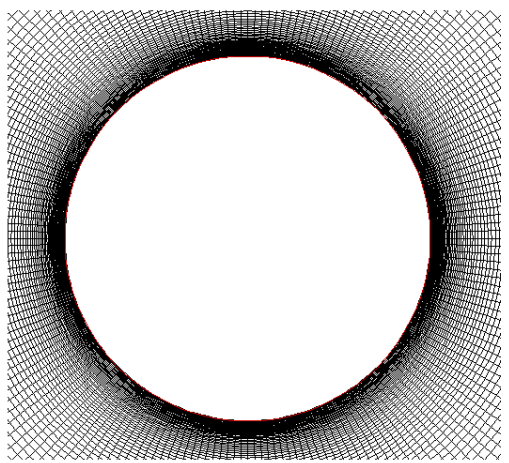

Şekil 2. Ağ yapısının genel görünümü (a) ve silindir etrafındaki ağ yapısı detayı (b) 
Çözümler sonlu hacimler metodunu kullanan ANSYS FLUENT 18.1 yazılımı kullanılarak 2 adet E31240 v5 işlemcili 32 GB RAM'e sahip bir bilgisayar ile yapılmıştır. Tüm türbülans modellerinde hız ve basınç eşleştirmesi için PISO (Pressure-Implicit with Splitting of Operators), basınç ayrıklaştırması için PRESTO! basınç ayrıklaştırması için sınırlandırılmış merkezi farklar ve daimi olmayan formülasyon için de ikinci dereceden açık formülasyon kullanılmıştır.

LES için Smagorinsky-Lilly alt ağ modellemesi kullanılmıştır. DES için RANS tabanı olarak k-w SST modeli seçilmiştir, k- $\varepsilon$ modeli içinse ayrılmalı akışlar için daha uygun olan Reliazable modeli seçilmiştir. Realizable k- $\varepsilon$ modeli, türbülans kinetik enerjisi k, dağılma (dissipation) oranı $\varepsilon$ değerini ele alarak hesaplayan bir model olup özellikle ayrılmalı akışlarda başarısı daha yüksektir. Türbülans viskozitesini hesaplama yöntemindeki farklılıktan dolayı diğer k- $\mathrm{k}$ modellerinden ayrılır [15]. Türbülansa geçiş modeli olan üç denklemli $\mathrm{k}-\mathrm{k}_{\mathrm{L}}-\omega$ Transition modelinde ise $\mathrm{k}$ türbülans kinetik enerjiyi, $\mathrm{k}_{\mathrm{L}}$ laminer kinetik enerjiyi, $\omega$ ise ters türbülans zaman ölçeğini göstermekte olup sınır tabakanın türbülansa geçişinin olduğu durumları modellemek üzere geliştirilmiştir. LES modelinde büyük girdaplar doğrudan çözülürken küçük girdaplar modellenir, bu modellemede alt ağ (subgrid) girdap viskozitesini modellemek oldukça önemlidir. Mevcut çalışmada Smagorinsky-Lilly modeli kullanılmıştır. DES yaklaşımı hibrid RANS/LES yaklaşımı olarak da bilinen bu modelde sınır tabaka içerisinde seçilen RANS yaklaşımına göre, ayrılmış bölgede ise LES yaklaşımına göre modelleme yapar. Bu çalışmada k- $\omega$ tabanlı DES kullanılmıştır, k türbülans kinetik enerjiyi, $\omega$ ise özgün dağılma hızını ele alarak modelleme yapar. Türbülans modellerinin detayları ve formülasyonları için ANSYS Fluent yazılımının teori rehberine [15] başvurulabilir.



Şekil 3. Farklı düğüm noktası sayışınsa sahip ağlarda ortalama sürükleme katsayıları

Tüm çözümler Reynolds sayısı $\mathrm{Re}=5000$ 'de gerçekleştirilmiştir. Zaman adımı $\Delta \mathrm{t}=5 \times 10^{-5} \mathrm{~s}$ olarak ayarlanmıştır ve böylece CFL sayısı 1'in altında tutulmuştur. Akış rejime oturduktan sonra, 200D/V olacak şekilde örnekleme alınmış ortalama için bu örneklemede alınan değerler kullanılmıştır, bu örnekleme süresi Zhang vd. [16] tarafından da belirtildiği ortalama akış yapısını çıkarmak için bu süre yeterlidir. Silindir üzerindeki akış karakteristikleri ve kuvvet katsayıları, Reynolds sayısı yanında blokaj oranı, serbest akış türbülans şiddeti, silindir yüzey pürüzlülüğü gibi bir çok parametreye bağlıdır. Dolayısıyla bu çalışmada elde edilen sonuçlar, aynı Reynolds sayısında yapılan deneysel çalışma [17] ile kıyaslanmıştır. Bu çalışmada akış yapısı su kanalında PIV (Particle Image Velocimetry-Parçaçık Görüntülemeli Hız Ölçümü) ile çıkarılmış, sürükleme kuvveti ise rüzgâr tünelinde ölçülmüştür.

Reynolds sayısı, sürükleme katsayısı ve Strouhal sayısı aşağıdaki formüllere göre hesaplanmıştır.

$$
\begin{aligned}
R e & =\frac{\rho V D}{\mu} \\
C_{D} & =\frac{F_{D}}{\frac{1}{2} \rho V^{2} A}
\end{aligned}
$$




$$
S t=\frac{f D}{V}
$$

Bu formüllerde, $\rho$ akışkanın yoğunluğunu, V serbest akış hızını, D silindirin çapını, $\mu$ akışkanın dinamik viskozitesini, $F_{D}$ sürüklenme kuvvetini hızını, A silindirin ön görünüş alanı olan çap ve boyunun çarpımını (DL), $\mathrm{f}$ ise $\mathrm{C}_{\mathrm{L}}$ değerlerinden alınan baskın frekansı simgelemektedir.

\section{BULGULAR VE TARTIŞMA}

Silindir arkasında art izindeki zaman ortalamalı akış yapısı incelendiğinde ters akış oluşum bölgesinde odak noktaları $\mathrm{F}$ ile gösterilen birbirine ters dönen iki girdap ve bir adet de ayrılma noktası $\mathrm{S}$ olduğu görülür. F ve S noktaları silindir etrafındaki akışın topolojinin belirlenmesinde kullanılan en önemli parametrelerdendir. Şekil 4'de sayısal zaman ortalamalı akım çizgileri verilmiştir. Kıyaslamanın doğru yapılabilmesi için deneysel çalışmanın koordinatları silindir çapı D ile boyutsuzlaştırılarak verilmiş ve silindir merkezi x/D= -0.5 'de olacak şekilde konumlandırılmıştır. Deneysel çalışmada S noktası silindirin arka yüzeyinden yaklaşık 1.4D mesafede oluşmuş ve bu mesafe LES modelinde 1.35D, DES modelinde 1.25D olarak tahmin edilmiştir. RANS modellerinde ise fark çok daha fazla çıkmış ve $\mathrm{k}-\mathrm{k}_{\mathrm{L}}-\omega$ Transition modelinde $0.52 \mathrm{D}, \mathrm{k}-\varepsilon$ Realizable modelinde ise $1.05 \mathrm{D}$ olarak elde edilmiştir. Deneyselde 0.8D olan F değeri ise LES modeli ile $0.76 \mathrm{D}$, DES ile $0.68 \mathrm{D}, \mathrm{k}-\mathrm{kL}-\omega$ Transition modeli ile $0.2 \mathrm{D}, \mathrm{k}-\varepsilon$ Realizable modeli ile de $0.57 \mathrm{D}$ olarak tahmin edilmiştir. Deneysel ve sayısal F ve S noktaları silindirin çapı D cinsinden Tablo 1'de özetlenmiştir. Şekil 4'deki zaman ortalamalı akım çizgileri detaylı incelendiğinde LES ve DES modellerinde küçük ayrılma kabarcıklarının oluştuğunu görmek mümkündür. Silindir etrafındaki akışın PIV deneylerinde lazerde parlamadan kaynaklı olarak genelde deneylerde görülemese de bu kabarcıkların oluşması beklenen bir durumdur. Eğer k-k $\mathrm{k}_{\mathrm{L}}-\omega$ Transition modelinde bu kabarcık çok büyük ve iki parçalı şekilde tahmin edilmişken k-E Realizable modelinde ise kabarcık hiç görülememiştir.
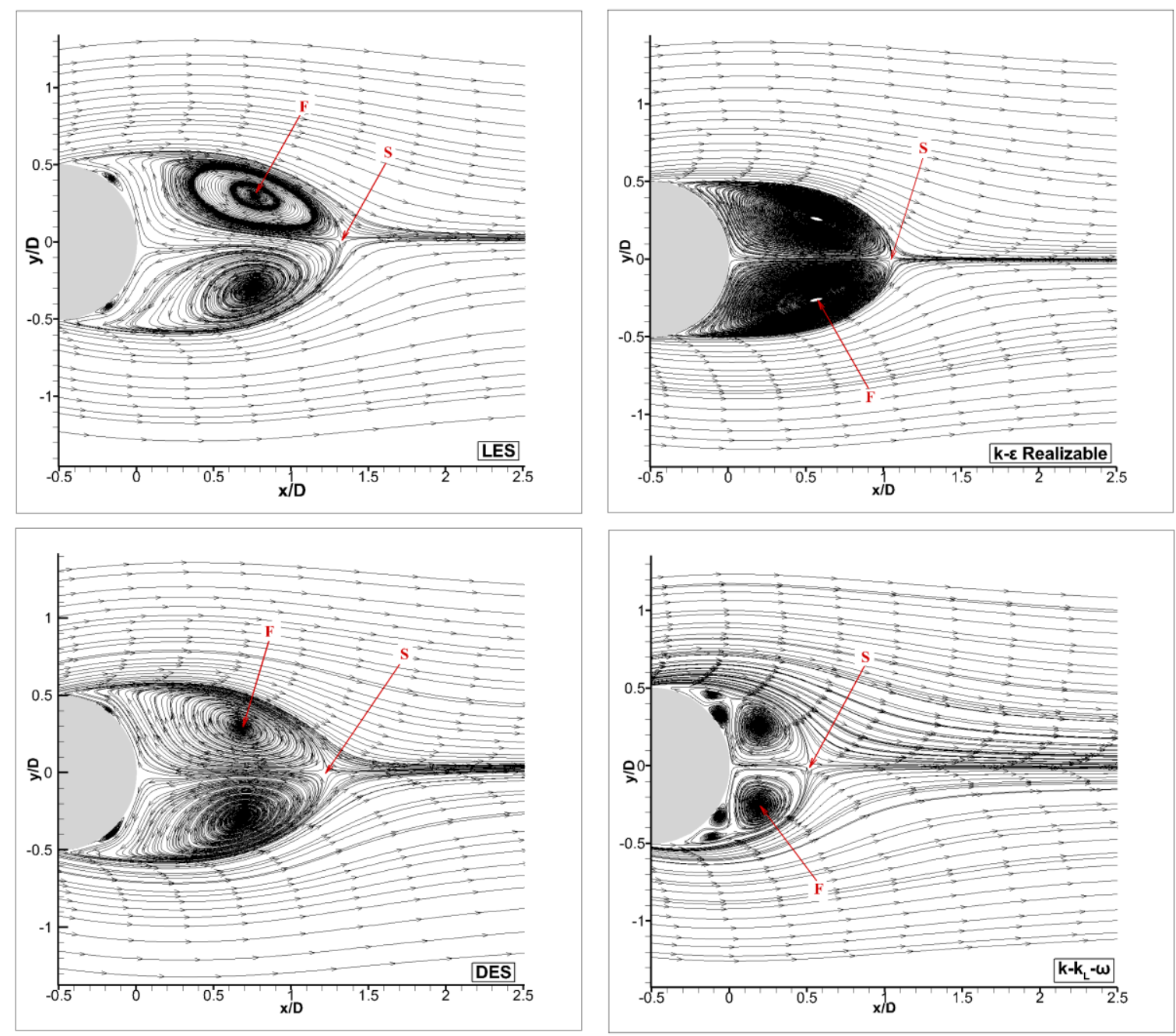

Şekil 4. Sayısal zaman ortalamalı akım çizgileri 
Tablo 1. Deneysel ve sayısal ortalama sürükleme katsayısı $\left(\mathrm{C}_{\mathrm{D}}\right)$ değerleri

\begin{tabular}{ccc}
\hline Model & F & S \\
\hline Deneysel [17] & 0.8 & 1.4 \\
LES & 0.76 & 1.35 \\
DES & 0.68 & 1.25 \\
k-k $\mathrm{k}_{\mathrm{L}} \omega$ Transition & 0.2 & 0.52 \\
k- $\varepsilon$ Realiazable & 0.57 & 1.05 \\
\hline
\end{tabular}

Ortalama sürükleme katsayısı $\mathrm{C}_{\mathrm{D}}$ değerleri için elde edilen sonuçlar Tablo 2'de verilmiştir. Deneysel olarak elde edilen 1.07 olan $C_{D}$ değeri; LES modelinde $\% 3$ fark ile 1.04, DES modelinde \%4 fark ile 1.03 olarak tahmin edilmiştir. URANS modellerinde ise $\mathrm{k}-\mathrm{k}_{\mathrm{L}}-\omega$ modeli yaklaşı $\% 26$ fark ile 1.30 değeriyle daha yüksek, $\mathrm{k}-\varepsilon$ Realizable modelinde ise \%18 fark ile 0.84 değeriyle daha düşük olarak tahmin etmiştir.

Tablo 2. Deneysel ve sayısal ortalama sürükleme katsayısı $\left(C_{D}\right)$ değerleri

\begin{tabular}{ccc}
\hline Model & $\mathbf{C}_{\mathbf{D}}$ & Fark (\%) \\
\hline Deneysel [17] & 1.07 & 0 \\
LES & 1.04 & -3.12 \\
DES & 1.03 & -4.11 \\
$k-k_{\mathrm{L}}-\omega$ Transition & 1.30 & 25.81 \\
$\mathrm{k}-\varepsilon$ Realiazable & 0.84 & -18.13 \\
\hline
\end{tabular}

Kararsız akış için önemli olan bir diğer parametre de St sayısı olup bu sayı tüm modeller için incelenmiştir. Tablo 3 elde edilen St sayılarını göstermektedir. Sayısal çalışmalar için baskın frekans, literatürde de belirtildiği gibi anlık olarak kaydedilen taşıma kuvveti katsayısı $C_{L}$ üzerinden FFT değeri yapılarak hesaplanmıştır. Deneysel çalışmada 0.20 olan St sayısı LES, DES ve k-kL- $\omega$ modelleri için çok iyi tahmin edilmişken, k-E Realiazable modeli 0.25 ile deneysele en uzak tahmini yapmıştır. Her ne kadar akış yapısı LES ve DES modellerinden oldukça farklı çıksa bile St sayısının aynı çıkması şunu göstermiştir ki akışta girdap kopma frekansı veya $\mathrm{C}_{\mathrm{D}}$ ortalama akış yapısına bağlı değildir.

Tablo 3. Deneysel ve sayısal St Sayıları

\begin{tabular}{cc}
\hline Model & St \\
\hline Deneysel [17] & 0.20 \\
LES & 0.20 \\
DES & 0.20 \\
k-k $\mathrm{k}_{\mathrm{L}}-\omega$ & 0.20 \\
$\mathrm{k}-\varepsilon$ Realiazable & 0.25 \\
\hline
\end{tabular}

Sonuçların bazılarının farklı olmasının en temel sebebi RANS modellerinin oluşan küçük girdapçıkları modelleyememesidir. Eğer anlık değerleri incelenirse girdap yapısının oldukça farklı olduğu görülecektir. Anlık çevrinti $\left(w=\frac{\delta v}{\delta x}-\frac{\delta u}{\delta y}\right)$ kontürleri Şekil 5'de incelenen tüm modeller için gösterilmiştir. Kesik çizgiler negatif, düz çizgiler ise pozitif çevrinti değerlerini vermektedir. Anlık değerlerden görüleceği üzere RANS modelleri girdapları daha büyük kümeler halinde tahmin ederken, LES çok daha küçük parçalar halinde karmaşık şekilde sunmuştur ki bu gerçek akışta olan durumdur.

Norberg [18] tarafından da belirtildiği gibi Re=5000'de silindir etrafındaki akışın türbülansa geçişi art iz bölgesinde gerçekleşmektedir. Bu da akış modellemesini daha da karışık hale getiren bir durumdur. Özellikle tam türbülanslı akışlar için geliştirilen RANS modellerinin tahmin konusundaki başarısızlığını arttıran bir faktördür. Bunun yanında, bu çalışmada kullanılan $\mathrm{k}-\mathrm{k}_{\mathrm{L}}-\omega$ türbülansa geçiş modeli de silindir etrafındaki düşük Reynolds sayılı akış yapısını tahmin konusunda başarısız olmuş ve bu başarısızlığın sebebi türbülansa geçiş işleminin sınır tabakada gerçekleşmemesidir. Sonuç olarak, bu çalışmada silindir gibi önemli akış olayları yüzey dışında gelişen sistemlerde modelleme için LES veya DES modellerini kullanmanın daha uygun olduğu görülmüştür.

\section{SONUÇLAR}

Bu çalışmada silindir etrafındaki kararsız akış LES, DES, k- $\varepsilon$ Realizable ve k-k $\mathrm{k}_{\mathrm{L}}-\omega$ modelleriyle 5000 Reynolds sayısında incelenmiş ve literatürdeki bir deneysel çalışma ile kıyaslanmıştır. Daimi akış için önemli olan zaman ortalamalı akım çizgileri, sürüklenme katsayısı, Strouhal sayısı değerleri deneysel çalışma ile 
kıyaslanmıştır. Her 3 parametre için de LES modeli en iyi sonucu vermiştir, DES de LES kadar başarılı olamasa da URANS modellerine göre daha iyi performans göstermiştir. URANS modellerinden k- $\varepsilon$ Realizable akış yapısını LES ve DES kadar başarılı olamasa da $\mathrm{k}-\mathrm{k}_{\mathrm{L}}-\omega$ modelinden daha iyi tahmin etmiştir. Ancak ortalama sürükleme katsayısını deneysele göre yaklaşık \%18 düşük bulmuş aynı zamanda St sayısı konusunda deneysele göre farklı sonuç veren tek model olmuştur. Anlık akış yapısını çok büyük farkla tahmin eden $\mathrm{k}-\mathrm{k}_{\mathrm{L}}-\omega$ modeli sürükleme katsayını deneyselden \% 25 daha fazla bulmasına rağmen St sayısında deneyselle gayet iyi bir uyum göstermiştir. Sonuç olarak, bu çalışmada silindir gibi küt cisimlerde dış akışın modellenmesinde için doğrudan akış yapısını çözümleme yoluna giden LES veya DES türbülans modellerinin kullanılmasının daha uygun olduğu görülmüştür.
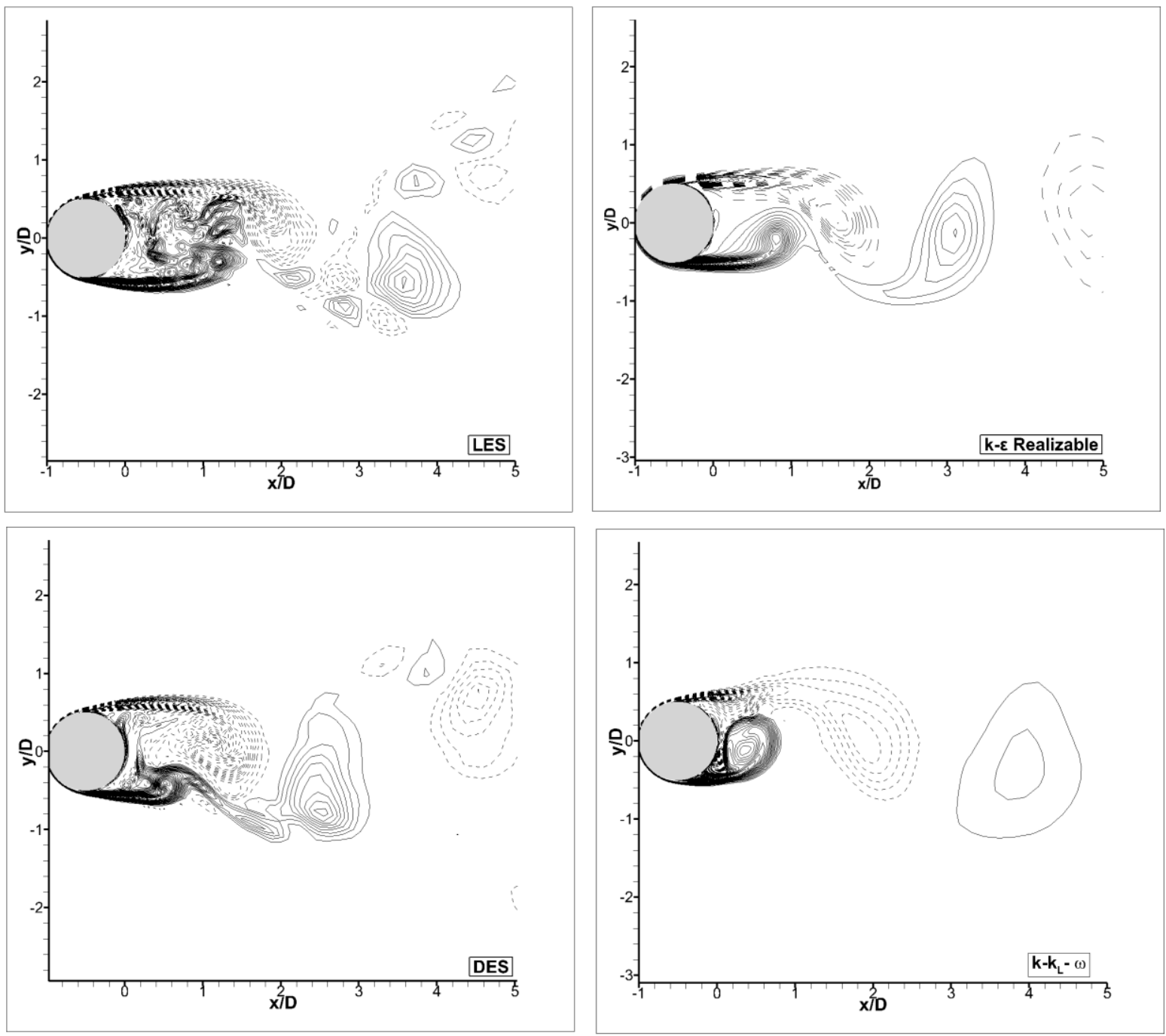

Şekil 5. Anlık çevrinti konturları

\section{KAYNAKLAR}

[1] Pinar, E., Ozkan, G. M., Durhasan, T., Aksoy, M. M., Akilli, H., \& Sahin, B. (2015). Flow structure around perforated cylinders in shallow water. Journal of Fluids and Structures, 55, 52-63.

[2] Ozgoren, M., Pinar, E., Sahin, B., \& Akilli, H. (2011). Comparison of flow structures in the downstream region of a cylinder and sphere. International Journal of Heat and Fluid Flow, 32(6), 1138-1146.

[3] Rashidi, S., Hayatdavoodi, M., \& Esfahani, J. A. (2016). Vortex shedding suppression and wake control: A review. Ocean Engineering, 126, 57-80 
[4] Najafi, L., Firat, E., \& Akilli, H. (2016). Time-averaged near-wake of a yawed cylinder. Ocean Engineering, 113, 335-349

[5] Young M. E. \& Ooi A. (2007). Comparative Assessment of LES and URANS for Flow Over a Cylinder at a Reynolds Number of 3900. 16th Australasian Fluid Mechanics Conference. 2-7 December, Gold Coast, Australia, 1063-1070.

[6] Palkin, E., Mullyadzhanov, R., Hadžiabdić, M., \& Hanjalić, K. (2016). Scrutinizing URANS in shedding flows: the case of cylinder in cross-flow in the subcritical regime. Flow, Turbulence and Combustion, 97(4), 1017-1046.

[7] Prsic, M. A., Ong, M. C., Pettersen, B., \& Myrhaug, D. (2014). Large Eddy Simulations of flow around a smooth circular cylinder in a uniform current in the subcritical flow regime. Ocean Engineering, 77, 61-73.

[8] Rosetti, G. F., Vaz, G., \& Fujarra, A. L. (2012). URANS calculations for smooth circular cylinder flow in a wide range of Reynolds numbers: solution verification and validation. Journal of Fluids Engineering, 134(12), 121103.

[9] Mannini, C. (2015). Applicability of URANS and DES simulations of flow past rectangular cylinders and bridge sections. Computation, 3(3), 479-508.

[10] Kim, S., Wilson, P. A., \& Chen, Z. M. (2015). Large-eddy simulation of the turbulent near wake behind a circular cylinder: Reynolds number effect. Applied Ocean Research, 49, 1-8.

[11] Sidebottom, W., Ooi, A., \& Jones, D. (2015). A parametric study of turbulent flow past a circular cylinder using large eddy simulation. Journal of Fluids Engineering, 137(9), 091202.

[12] You, J. Y., \& Kwon, O. J. (2010). Numerical comparisons between URANS and hybrid RANS/LES at a high reynolds number flow using unstructured meshes. International Journal of Aeronautical and Space Sciences, 11(1), 41-48.

[13] Tian, X., Ong, M. C., Yang, J., \& Myrhaug, D. (2013). Unsteady RANS simulations of flow around rectangular cylinders with different aspect ratios. Ocean Engineering, 58, 208-216.

[14] Soydan, N. G., Şimşek, O., \& Aköz, M. S. Köprü Ayağı Etrafındaki Türbülanslı Akımın Sayısal ve Deneysel Analizi. Politeknik Dergisi, 21(1), 137-147

[15] Fluent, A. N. S. Y. S. (2018). Ansys Fluent Theory Guide. ANSYS Inc., USA.

[16] Zhang, H., Yang, J. M., Xiao, L. F., \& Lu, H. N. (2015). Large-eddy simulation of the flow past both finite and infinite circular cylinders at $\mathrm{Re}=3900$. Journal of Hydrodynamics, 27(2), 195-203.Zhang, H., Yang, J. M., Xiao, L. F., and Lü, H. N.,2015

[17] Ozkan, G. M., Firat, E., \& Akilli, H. (2017). Passive flow control in the near wake of a circular cylinder using attached permeable and inclined short plates. Ocean Engineering, 134, 35-49.

[18] Norberg C. (1998). LDV-measurements in the near wake of a circular cylinder. Advances in Understanding of Bluff Body Wakes and Vortex-Induced Vibration. 21-25 June, Washington DC, USA,1-1 